\title{
Relating Colorimeter Measurement of Plant Color to the Royal Horticultural Society Colour Chart
}

\author{
Donald H. Voss \\ 8602 Pepperdine Drive, Vienna, VA 22180
}

Communicating perceptions of color entails not only evaluation and description of colors by one individual but also the visualization by another of the colors described. Color charts have long played a unique intermediary role in this process. Visual color evaluation, however, is often flawed. The increased availability of portable color-measuring instruments now makes possible a more objective notation of specimen colors, and the method detailed here facilitates reference to the closest color chip in the Royal Horticultural Society Colour Chart.

After surveying many color charts used by biologists for biological descriptions, Tucker et al. (1991) recommended using the Royal Horticultural Society (RHS) chart. They observe that the RHS chart was designed for horticultural taxa. (It does not, for example, sample extensively the color range of fungi.) I also recommend the RHS chart, but stress that color-evaluation technique is an essential and critical-though often neglectedaspect of color description.

Careful color evaluation is desirable for botanical and horticultural descriptions. It is true that botanical descriptions commonly have not included detailed color references because, inter alia, color is not well preserved in most herbarium specimens. Some botanical exploration is, however, devoted to the search for plants with superior horticultural characteristics, including color. Moreover, though color may not supply important taxonomic distinctions among plants in a group as presently known, it may assume greater importance as new taxa are discovered.

Both evaluating color and determining

Received for publication 28 Feb. 1992. Accepted for publication 30 June 1992. I am deeply indebted to William N. Hale, Hale Color Consultants, Phoenix, Md., for continued generosity in providing guidance, use of a spectrophotometer to measure selected color chips, and recommendations incorporated in this article. Hale was president of Munsell Color Co. and has been chairman of Committee E-12 on Appearance, American Society for Testing and Materials. Richard McCarty, Spectroscopy Systems, Silver Spring, Md., assisted with information on instrumentation. Both read the draft article, and T.R. Dudley, U.S. National Arboretum, read it from the professional botanist's viewpoint. Any errors or infelicities are, of course, solely my responsibility. The use of trade names does not imply endorsement of the products named nor criticism of similar products not named. which RHS color chip (or "bracketing" chips) most closely represents a color can be accomplished efficiently by using a photoelectric tristimulus colorimeter with the procedure described below. This procedure offers a more objective notation of color and a greater reduction in the potential for human error in color evaluation than use of the chart.

Instrumental measurement provides a readily replicated description of color because it avoids the effects of differences in the spectral characteristics of daylight at various times or differences among artificial light sources. Similarly, it avoids the effects of differences in color perception among human observers.

\section{Is the method practical?}

For a method to be adopted, it must meet the test of practicality. Three of the relevant considerations are:

- The degree of precision in color notation sufficient for diagnosis or identification of a specimen.

- The equipment requirement.

- The site, whether laboratory or field.

The precision required in color evaluation depends on the objectives to be served. In botanical taxonomy, color may be diagnostic (e.g., whether fruit is red or black in Ilex or Viburnum), but a general description of the color has usually been considered adequate. Not so with cultivars! Many are virtually indistinguishable except for subtle color differences that require careful evaluation.

Once a decision is made to evaluate color, appropriate equipment must be selected. Technical factors are discussed later; now, only weight is considered. The minimum equipment is a color chart in excellent condition; carried in the field, a copy of the RHS chart adds $\approx 1 \mathrm{~kg}$ to the impedimenta. A colorimeter such as that described below would add $\approx 2$ to $3 \mathrm{~kg}$, depending on the supply of AA batteries carried (a padded luggage-type case would be another $3 \mathrm{~kg}$ ).

The color chart and colorimeter are readily accommodated in the laboratory. But in the field . . .? A botanist leaving the laboratory in a research institution may travel a few hundred meters to a test plot and be "in the field." Or one may travel to remote areas in western China and be "in the field." Ultimately, the practicality of carrying equipment to the site involves balancing the logistical burden against the importance of precise color evaluation to the accomplishment of the mission.

Pitfalls in visual color evaluation. An important aspect to consider when choosing a method is that visual evaluation is tricky. A specimen's color should be compared to color chips with about the same level of lightness ("value" in Munsell terminology) as the specimen. But adjacent leaves in any one of the four color fans of the RHS chart often represent widely differing levels of lightness and color saturation (Munsell "chroma" at a given level of lightness). Because of this arrangement, one must fish around to find color chips that are many leaves apart in the color fan-or worse, in different fans.

Visual color evaluation may be impaired by a lack of attention to essential technical requirements. These include using north-sky daylight (or special sources with similar spectral characteristics-not ordinary indoor light sources), avoiding natural light during early morning and late afternoon (when it is distinctly reddish), using a hue-neutral background, limiting the visual field to the specimen and only those color chips involved in the evaluation, and avoiding specular reflection of the light source from either specimen or color chips. Technical requirements are more fully and precisely stated in "Practice for Visual Evaluation of Color Differences of Opaque Materials" (Amer. Soc. for Testing and Materials, 1991). The botanist or horticulturist undertaking color evaluation will also find a great deal of useful background information in a basic colorimetry text such as that of Judd and Wyszecki (1975).

An additional essential element in visual color evaluation is the color sensitivity of the observer. Judd and Wyszecki (1975) cited a study indicating that the incidence of some degree of deviation from normal color vision is $\approx 8 \%$ among males and $0.4 \%$ among females. Even among those with normal color vision, there is a range of variation in response to color stimuli. In addition to the usual color-blindness tests, a simple test is available to determine the ability of individual observers to discriminate between very similar colors (Farnsworth, 1957).

\section{A coordinate system of color notation}

Before discussing color measurement further, it is necessary to describe the metric employed, as well as the nature of the gamut of colors. The Commission Internationale de l'Eclairage [International Commission on Il- 
lumination (CIE)] 1976, or CIELAB, system (CIE, 1978) established a system of numerical coordinates to locate individual colors in a "color solid" based on uniform visual color spacing. (The CIE promotes the standardization of colorimetric practice with special attention to the scientifically and industrially important problems of color discrimination and color spacing.)

A color solid is a three-dimensional geometric representation of the colors in a given color gamut. As a first step in visualizing the color solid, consider a peeled grapefruit with its axis vertical. The segments of the fruit are arranged radially around the axis. In the color solid, the central axis is an achromatic scale, with white at the top, black at the bottom, and grays between. Roughly corresponding in form to the segments of the grapefruit are segments of the color solid representing the hues, e.g., red, orange, yellow, green, blue, violet, purple. Near the central axis, the colors are grayish; near the outer surface of the color solid, they are saturated or "pure." Figure 1 illustrates the relative positions of light and dark, grayish, and saturated colors in the purple segment of a color solid.

Unlike the grapefruit, the color solid is not symmetrical. The high-chroma yellows are relatively light colors (in the upper half of the grapefruit). Conversely, the high-chroma reds and purples are relatively dark colors (in the lower half of the grapefruit). Thus, in the lighter colors, the surface of the color solid bulges out in the yellow hue range; for the darker colors, it bulges out in the red-topurple hue range.

The axes of the color solid are designated as $\mathrm{L}^{*}, \mathrm{a}^{*}$, and $\mathrm{b}^{*}$ (pronounced "L-star," etc.). $L^{*}$, corresponding to the vertical axis of the grapefruit, is a measure of lightness related nonlinearly to the CIE 1931 coordinate $\mathrm{Y}$, which is the reflectance factor, in percent, For the plane representing a given value of $\mathrm{L}^{*}$ (i.e., a horizontal cross section of the grapefruit), $a^{*}$ is a positive or negative coordinate defining a locus relative to a purplish-red-bluish-green axis; and $b^{*}$ is a positive or negative coordinate defining a locus relative to a yellow-blue axis. The area near the origin (very low absolute values of $a^{*}$ and $\left.b^{*}\right)$ represents grays, i.e., colors of little or no chromaticity. As a* and/or b* increase absolutely (i.e., in either a positive or negative direction), chromaticity increases. Figure 2 shows the general hue sequence on the $a^{*}, b^{*}$ plane.

The CIELAB color space thus may be visualized as a stack of rectangular-coordinate graphs, each with $a^{*}$ measuring distance along the abscissa axis and $b^{*}$ measuring distance along the ordinate axis. Those at the top of the stack have high $\mathrm{L}^{*}$ (white or near-white colors); those near the bottom have low $\mathrm{L}^{*}$ (black or near-black colors).

\section{Instruments for color evaluation}

A spectrophotometer provides the most accurate color-space coordinates. It measures the reflectance of a specimen throughout the visible spectrum from $\approx 380$ to 780

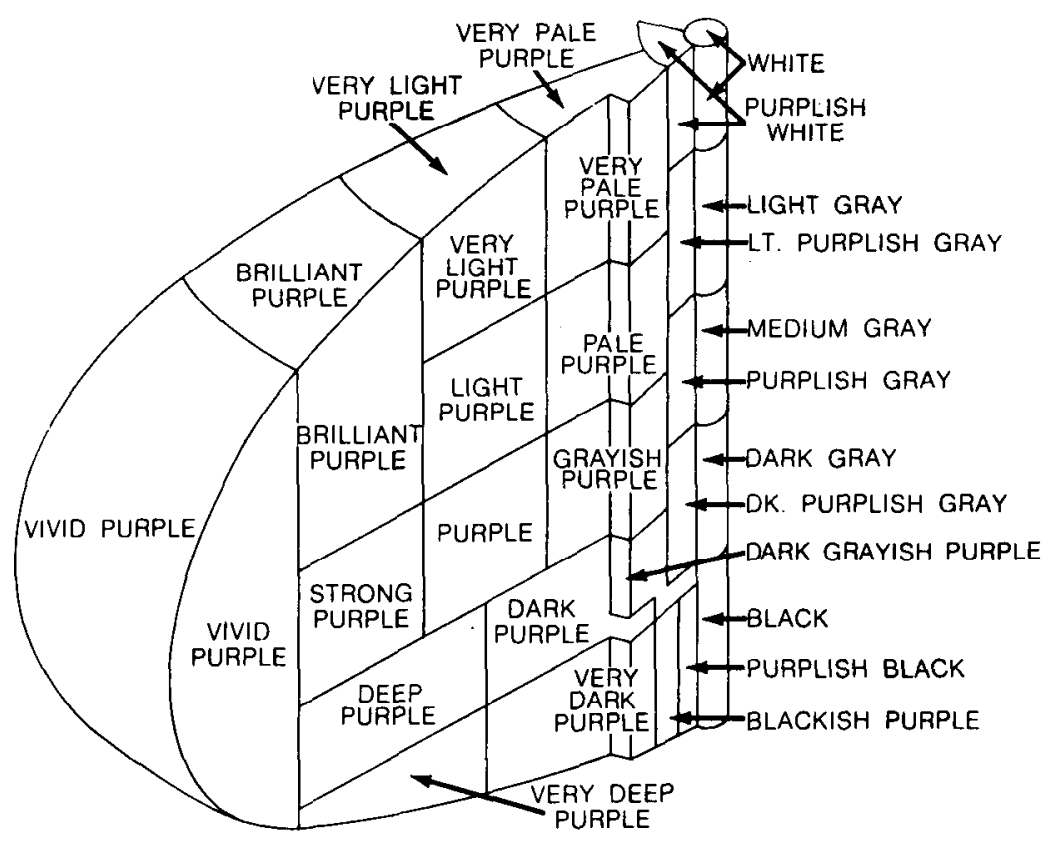

Fig. 1. Purple segment of the color solid (Fig. 6 in Kelly and Judd, 1976).

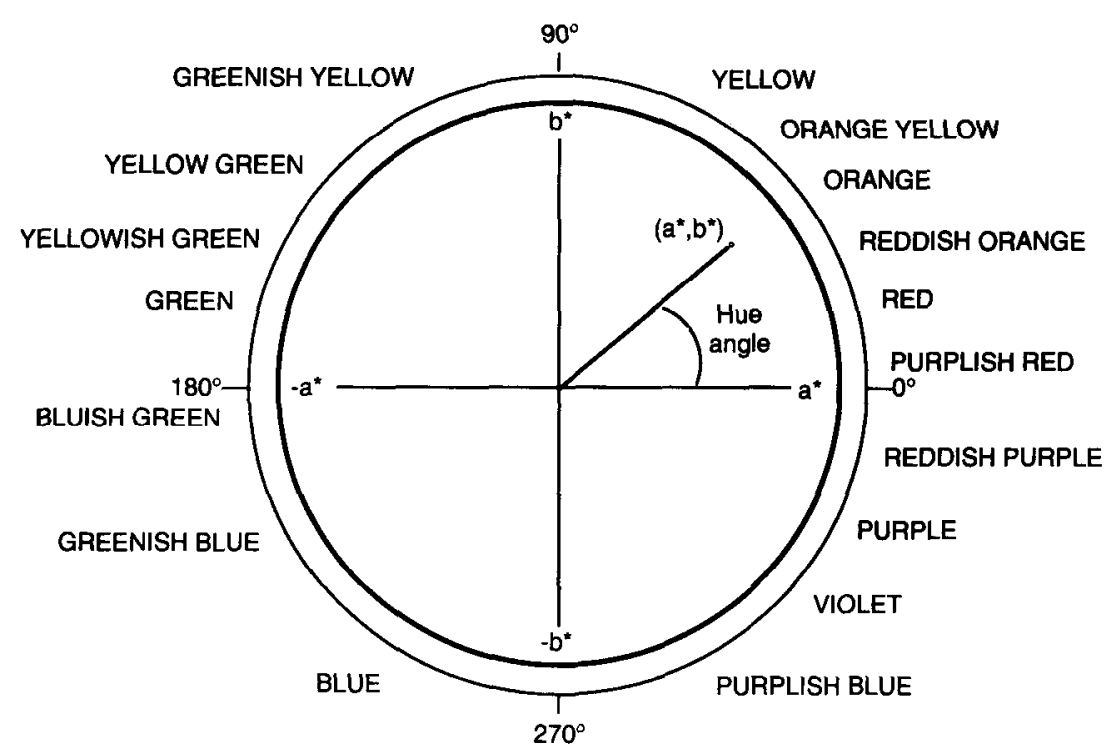

Fig. 2. Hue sequence and hue-angle orientation on a CIELAB diagram (with ISCC-NBS color names).

$\mathrm{nm}$ at, for example, 10 -nm intervals. The spectrophotometer then numerically characterizes the appearance of the color under a specified "Standard Illuminant" (e.g., D65 daylight) to a "Standard Observer," and then reports the coordinates in a visual or printed display. Unlike the spectrophotometer, the photoelectric tristimulus colorimeter reports coordinates based on integrated spectral responses. Lacking the inherent accuracy of the spectrophotometer, it functions best to measure color differences.

The research worker interested in a costeffective method to evaluate plant colors must weigh the high accuracy and precision of the spectrophotometer against the degree of variability of color commonly present in the material being studied. For a given botanical taxon or horticultural variety, the value and chroma and perhaps even hue may vary somewhat on the same plant, between adjacent plants, or among plants in different habitats. In some plants, flower color changes perceptibly as the flower ages. Traditionally, flower color is evaluated at anthesis. Color notations for other stages (early or late bud stage, e.g.) should be recorded.

Variations of the sort noted are usually far greater than the minimum detectable by a spectrophotometer and can be readily detected by a good colorimeter. In brief, a spectrophotometer may be overkill (as well as over budget) for many botanical and horticultural applications. Where the spectral 
characteristics of the color are relevant to research objectives, the spectrophotometer is, of course, essential.

In the past few years, a variety of portable color-measuring instruments has become available (Table 1). Technical capabilities aside, there are many aspects to consider when choosing an instrument, e.g., overall weight and compactness on the one hand and ease of handling (especially when taking measurements) on the other. A single unit may be more convenient to carry than a measuring head connected by cable to its data processing unit; but the lightness of the separate measuring head may prove to be advantageous when placing the aperture of the instrument over the desired area of the specimen.

The size of specimen color areas to be evaluated must be considered when selecting an appropriate measurement-area diameter (Table 1). A 50-mm diameter might be fine for banana leaves but useless for the much smaller leaves and flower petals on a wide range of ornamental plants. At the other extreme, a 3-mm aperture may isolate a colorvariant sector on an azalea petal but produce a misleading evaluation of a larger area of somewhat mottled color. The user needs to remember that the minimum specimen size must be at least as large as the area illuminated by the instrument-an area that is usually several millimeters larger in diameter than the measured area. For the procedure presented in this article, the use of an instrument with a d (diffuse) $/ 0^{\circ}$ or $\mathrm{d} / 8^{\circ}$ illuminating viewing geometry is recommended (W.N. Hale, personal communication).

An important feature of the Minolta CR300 colorimeter I used is its provision of 19 channels for user-supplied calibration references in addition to the primary channel for the standard white plate provided with the instrument. Each color measured is evaluated in terms of its color difference from the nearest calibration reference. By calibrating the 19 optional channels with 18 spectrophotometrically measured high-chroma colors distributed around the hue circle and a middle value, essentially hue-neutral gray, color evaluation is more accurate than that obtained when the instrument is calibrated only to the white plate.

\section{Linking measurement of specimen color to the color chart}

A personal computer (PC) program compares the colorimeter measurement of specimen color with stored measurements for each of the RHS color chips. It then identifies the chips closest in color to the specimen. The concept is simple-with a given instrument calibrated as described:

-Measure each of the 808 color chips in the RHS Colour Chart (1986?).

- Tabulate in the PC the resulting colorspace coordinates to provide a reference matrix of coordinates.

- Measure a specimen color and record the color-space coordinates. The instrument will store up to 300 measurements

Table 1. Some portable spectrophotometers and colorimeters.

\begin{tabular}{|c|c|c|c|c|c|}
\hline $\begin{array}{l}\text { Model and } \\
\text { approx. cost (\$) }\end{array}$ & $\begin{array}{c}\text { Measurement } \\
\text { mode }^{z}\end{array}$ & $\begin{array}{l}\text { Data output } \\
\text { mode }^{2}\end{array}$ & $\begin{array}{l}\text { Illuminating/ } \\
\text { viewing } \\
\text { geometry }\end{array}$ & $\begin{array}{l}\text { Diam of } \\
\text { measurement } \\
\text { area (mm) }\end{array}$ & Wt \\
\hline \multicolumn{6}{|l|}{ Hunter Assoc. Lab. } \\
\hline $\begin{array}{l}\text { MiniScan, } \\
\$ 7000-11.000\end{array}$ & $\mathrm{SP}$ & SP or TRI & $\begin{array}{r}\mathrm{d} / 8^{\circ} \\
45^{\circ} / 0^{\circ}\end{array}$ & $\begin{array}{c}8 \text { or } 25 \\
3.5 \text { or } 25.4\end{array}$ & 1800 \\
\hline \multicolumn{6}{|l|}{ Minolta $^{x}$} \\
\hline $\begin{array}{l}\text { CM-2002, } \$ 11,900 \\
\text { CR-300 }{ }^{\mathbf{w}}, \$ 5900 \\
\mathrm{CR}-310^{\mathbf{w}}, \$ 6200 \\
\mathrm{CR}-321^{\mathrm{w}}, \$ 6100 \\
\mathrm{CR}-331^{\mathbf{w}}, \$ 6500\end{array}$ & $\begin{array}{l}\text { SP } \\
\text { TRI } \\
\text { TRI } \\
\text { TRI } \\
\text { TRI }\end{array}$ & $\begin{array}{c}\text { SP or TRI } \\
\text { TRI } \\
\text { TRI } \\
\text { TRI } \\
\text { TRI }\end{array}$ & $\begin{array}{r}\mathrm{d} / 8^{\circ} \\
\mathrm{d} / 0^{\circ} \\
\mathrm{d} / 0^{\circ} \\
45^{\circ} / 0^{\circ} \\
45^{\circ} / 0^{\circ}\end{array}$ & $\begin{array}{r}8 \\
8 \\
50 \\
3 \\
25\end{array}$ & $\begin{array}{c}1600 \\
700 \text { (head) } \\
700 \text { (head) } \\
1250 \text { (head) } \\
1000 \text { (head) }\end{array}$ \\
\hline $\begin{array}{l}\text { X-Ritev } \\
\text { 968, } \$ 8000 \\
948, \$ 6000 \\
918, \$ 4000\end{array}$ & $\begin{array}{l}\text { SP } \\
\text { SP } \\
\text { TRI }\end{array}$ & $\begin{array}{c}\text { SP or TRI } \\
\text { TRI } \\
\text { TRI }\end{array}$ & $\begin{array}{l}0^{\circ} / 45^{\circ} \\
0^{\circ} / 45^{\circ} \\
0^{\circ} / 45^{\circ}\end{array}$ & $\begin{array}{c}4,8,20 \\
4,8,20 \\
1.7,3.4 \\
\text { or } 6.8\end{array}$ & $\begin{array}{r}1050 \\
1050 \\
800\end{array}$ \\
\hline
\end{tabular}

${ }^{2} \mathrm{SP}=$ spectral, $\mathrm{TRI}=$ tristimulus.

y 11491 Sunset Hills Road, Reston, VA 22090 . The price varies with internal refinements and software options.

×101 Williams Drive, Ramsey, NJ 07446.

"The instrument has a measuring head cabled to a data processor and display (wt $1.3 \mathrm{~kg}$ ) with thermaldot printer.

$\checkmark 3100$ 44th Street, Grandville, MI 49418.

and, optionally, will print the coordinates on a paper tape. In the field, the coordinates should be recorded in the field notebook.

- Determine the closest and next closest chips to the specimen color using a PC program to compare color differences calculated from the measured specimen coordinates and the measured color-chart coordinates.

- List the identification of the selected chips and a measure of their color differences from the specimen color.

- List the Inter-Society Color CouncilNational Bureau of Standards (ISCCNBS) color-names applicable to the selected chips (Huse and Kelly, 1984; note that the name for RHS chip 19B should be light yellow). These names are recommended because, unlike other color names, they convey information about hue, value, and chroma in a systematic and readily understood manner (see the color names in Fig. 1).

\section{Materials}

The RHS Colour Chart (Royal Hort. Soc., 1986?) was originally produced by the Royal Horticultural Society in 1966 and reissued in $\approx 1986$ as a joint publication with the Flower Council of Holland. Arrayed in four color fans (one of which contains grayed colors), the chart has 808 color chips on 202 leaves. Most of the colors are pigmented lacquers applied to the chart stock by a deposition process; however, some of the colors outside the opaque-lacquer gamut are printed using transparent inks. On each leaf, the color is successively "let down" (lightened) from the "A" chip to the "B," "C," and "D" chips. The chart is available from RHS Enterprises, Wisley, Woking, Surrey GU23 6QB, England, at a cost of $£ 30$. The most practical and economical means of payment is to sup- ply a VISA or Mastercard account number and expiration date with the order.

The Minolta CR-300 I used was equipped with the accessory "glass light-projection tube." The glass plate at the tip of this tube prevents moisture, mold, or other foreign matter present on specimens from contaminating the internal parts of the instrument. The permissible operating temperature of the instrument is from 0 to $40 \mathrm{C}$; the instrument should be stored between - 20 and 40C. The permissible relative humidity $(\mathrm{RH})$ is $<85 \%$ at $35 \mathrm{C}$ with no condensation.

The spectral response of the instrument closely matches the CIE 1931 Standard Observer curves. The CR-300 has diffuse illumination and $0^{\circ}$ viewing geometry (specular component included), and the diameter of the specimen aperture is $8 \mathrm{~mm}$. When reporting color measurements, an instrument's illumination and viewing geometry and its specimen aperture size should be noted. For computer cognoscenti, further automation of the process is possible in the laboratory: the CR-300 is equipped with a RS-232C terminal, and data can be transferred directly to a computer.

To replicate the results with other instruments of the same model, comparable calibration standards must be used. It is possible to specify commercially available plates, but I adopted a different procedure for two reasons. First, a set of nine or 10 such plates can cost about $\$ 1000$. Second, the user-selected references should provide colors at the outside of the color gamut of potential specimen colors, and the chroma of these may exceed the chroma gamut of some commercial plates.

To provide references to any user of the RHS chart, 18 high-chromaticity chips from the chart, well distributed around the hue circle, were measured with a Minolta CM1000 spectrophotometer; a middle-gray chip 
(202B) was measured with the colorimeter calibrated to spectrophotometrically determined coordinates for chips 202A and 202D (Table 2). Because of possible slight variations among different copies of the chart, spectrophotometric measurement of the designated 19 chips in the user's chart is desirable. The vendor of a colorimeter may be willing to supply these measurements.

A PC calculates the color difference between a specimen measurement and each of the recorded CR-300 measurements of the 808 chips in the color chart using the CIE$\mathrm{LAB}$ formulas. These are given in Recommendation 2 and the Appendix of CIE (1978). I use the "APL Plus" or "Pocket APL" language package [Manugistics, Inc. (formerly STSC)]. For 286-based or earlier PCs, Pocket APL provides great programming flexibility and computational power at a very moderate price (about \$100). Other software may, of course, be used for these computations.

\section{Procedures}

Careful preparation of the instrument is essential. For the CR-300, the "Index Set" routine is used to set several parameters: "print" = Y, "Color Space" = N, "Multi Measure" = Y, "Multi Cal." = Y, and "Light Source" = D65. The 00 channel is first calibrated using the white calibration plate supplied with the instrument. Then the other channels are calibrated successively with the 19 user-selected references-in this case the color chips listed in Table 2 . Subsequently, as long as the calibrations of channels 01 to 19 remain unchanged, the white-plate $(00)$ channel only is calibrated each time the instrument is turned on. If many measurements are being made, or if ambient temperature changes markedly during the period of use, the 00 channel should be recalibrated. During calibration (as well as when measuring specimen color), the measuring head should be held so that its axis is perpendicular to the plane of the color chip (or specimen surface).

After calibrating the instrument, the color chips are measured, and the resulting $\mathrm{Y}, \mathrm{x}$, $\mathrm{y}$ values are stored in the $\mathrm{PC}$ in an 808-row, three-column matrix. By means of an APL function using the CIELAB formulas, these data are converted to CIELAB coordinates. (The CR-300 will report CIELAB coordinates, but slightly greater accuracy results from converting to $\mathrm{L}^{*}, \mathrm{a}^{*}$, and $\mathrm{b}^{*}$ in the PC. The effects of small rounding errors when this conversion is done in the data processor of the CR-300 can be magnified by the squaring of terms in the color-difference formula used as the criterion for selecting the color chips closest to the specimen color.)

Another APL function accepts manual entry of the Y, $x, y$ coordinates from measurements of a specimen's color, converts these coordinates to CIELAB, and searches the 808-chip data matrix for the chips closest and next closest to the specimen's color. The criterion used in this step is color difference (the square root of the sum of the squares of the respective differences between specimen and color-chip values of $\mathrm{L}^{*}, \mathrm{a}^{*}$, and $\mathrm{b}^{*}$ ). The formula thus takes into account the difference in metric lightness and the chromaticity coordinates $\mathrm{a}^{*}$ and $\mathrm{b}^{*}$. The function then lists the two chips that have the smallest color differences from the specimen (see examples in Fig. 3).

The $\mathrm{L}^{*}, \mathrm{a}^{*}$, and $\mathrm{b}^{*}$ coordinates for the specimen and selected chips are supplemented by $C^{*}$ (a measure of chromaticity defined as the square root of the sum of the squares of $a^{*}$ and $b^{*}$ for a given color). Hue angle $\left[\arctan \left(\mathrm{b}^{*} / \mathrm{a}^{*}\right)\right.$ in the first quadrant] is often useful in interpreting color differences.

Table 2. Spectrophotometrically measured coordinates of user-selected Royal Horticultural Society color chart chips for calibration of the CR-300 ChromaMeter.

\begin{tabular}{lrcc}
\hline \hline \multirow{2}{*}{$\begin{array}{l}\text { RHS (1986) } \\
\text { chip no. }\end{array}$} & \multicolumn{3}{c}{ CIE coordinates } \\
\cline { 2 - 4 } & \multicolumn{1}{c}{$\mathrm{Y}$} & $\mathrm{x}$ & $\mathrm{y}$ \\
\hline $14 \mathrm{~A}$ & 64.26 & 0.4692 & 0.4613 \\
$23 \mathrm{~A}$ & 51.39 & 0.5028 & 0.4383 \\
$32 \mathrm{~A}$ & 25.79 & 0.5388 & 0.3581 \\
$40 \mathrm{~A}$ & 22.88 & 0.5568 & 0.3354 \\
$52 \mathrm{~A}$ & 19.17 & 0.5067 & 0.2991 \\
$57 \mathrm{~A}$ & 13.74 & 0.5062 & 0.2503 \\
$66 \mathrm{~A}$ & 12.87 & 0.4666 & 0.2284 \\
$74 \mathrm{~A}$ & 8.49 & 0.4237 & 0.2050 \\
$81 \mathrm{~A}$ & 12.62 & 0.2976 & 0.1647 \\
$88 \mathrm{~A}$ & 10.07 & 0.2485 & 0.1599 \\
$94 \mathrm{~A}$ & 9.23 & 0.2276 & 0.1812 \\
$104 \mathrm{~A}$ & 10.32 & 0.1936 & 0.1820 \\
$109 \mathrm{~A}$ & 14.69 & 0.1556 & 0.1917 \\
$113 \mathrm{~A}$ & 18.89 & 0.1961 & 0.2600 \\
$120 \mathrm{~A}$ & 23.35 & 0.2025 & 0.3001 \\
$130 \mathrm{~A}$ & 34.34 & 0.2620 & 0.4401 \\
$140 \mathrm{~A}$ & 25.32 & 0.2982 & 0.5290 \\
$154 \mathrm{~A}$ & 63.75 & 0.4017 & 0.4921 \\
$202 \mathrm{~B}$ & 16.07 & 0.3054 & 0.3195 \\
\hline
\end{tabular}

For those with normal color vision and good color-discrimination ability, a final step is to visually evaluate, under technically appropriate viewing conditions, the specimen in relation to the color chips selected by the procedure. This evaluation not only checks the selection but also facilitates the decision whether to cite only the closest color chip or to indicate a range between the closest and next closest.

The color-difference calculation gives equal weight to differences in $\mathrm{L}^{*}, \mathrm{a}^{*}$, and $\mathrm{b}^{*}$, so that lightness and chromaticity are implicitly factored in with hue. Because of the gaps between colors in any color chart, the closest color may be one that is not the closest when judged by hue alone. The formula can be adapted to give more weight to hue or to consider hue alone. But such changes can result in chip selection that em badly in terms of lightness and chromaticity. A visual check, combined with attention to the $\mathrm{C}^{*}$ (chromaticity) and hue-angle data in the computer listing, enables one to describe accurately the relationship of specimen color to the selected chips.

\section{Considerations relating to specimen characteristics}

Handling specimens, particularly translucent ones, calls for comment. Color evaluations may be influenced by the substrate, which should be hue-neutral; from my experiments, a white substrate yields the best results with the procedures outlined above. In general, measuring the petals on a black substrate indicates colors lower in reflectance and chromaticity than, and different in hue from, those selected visually.

1) ENTER SPECIMEN IDENTIFICATION:

CAMELLIA 'HIRYU NISHIKI', PETALS, 2 THICK, ON WHITE TILE

ENTER MEASURFD CAP $Y, X, Y$ FOR SPFCIMEN

$14.35 \quad 4480 \quad .2625$

\begin{tabular}{llllll} 
SPECIMEN & L $^{*}$ & $\mathrm{~A}^{*}$ & $\mathrm{~B}^{*}$ & $\mathrm{C}^{*}$ & HUE ANGLE \\
& $\mathbf{4 4 . 7 3}$ & $\mathbf{5 6 . 4 0}$ & -0.44 & $\mathbf{5 6 . 4 0}$ & $\mathbf{3 5 9 . 5}$ \\
\multicolumn{8}{c}{} & & & & \\
CLOSEST CHIP TO SPECIMEN & & & & \\
RHS86 63A dE* = 2.5 & $\mathbf{4 2 . 7 2}$ & $\mathbf{5 7 . 6 1}$ & -1.16 & $\mathbf{5 7 . 6 2}$ & $\mathbf{3 5 8 . 9}$ \\
ISCC-NBS 255 STRONG PURPLISH RED & & &
\end{tabular}

NEXT CLOSEST CHIP TO SPECIMEN

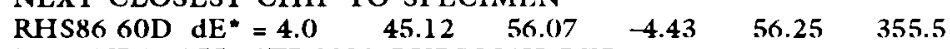

ISCC-NBS 255 STRONG PURPLISH RED

2) ENTER SPECIMEN IDENTIFICATION:

NYSSA SYLVATICA, FALL LEAF, I THICK, ON WHITE: TILE

ENTER MEASURED CAP Y,X,Y FOR SPECIMEN

$\begin{array}{llll}8.54 & .4761 & .3094\end{array}$

\begin{tabular}{|c|c|c|c|c|}
\hline SPECIMEN & $\begin{array}{l}A^{*} \\
38.36\end{array}$ & $\begin{array}{l}\mathrm{B} * \\
12.31\end{array}$ & $\begin{array}{l}C^{*} \\
40.29\end{array}$ & $\begin{array}{l}\text { HUE ANGLE } \\
17.8\end{array}$ \\
\hline $\begin{array}{l}\text { CLOSEST CHIP TO SPECIMEN } \\
\text { RHS86 } 185 \mathrm{~d} \text { dE }=6.530 .83 \\
\text { ISCC-NBS } 13 \text { DEEP RED }\end{array}$ & 38.76 & 7.40 & 39.46 & 10.8 \\
\hline $\begin{array}{l}\text { NEXT CLOSEST CHIP TO SPEC } \\
\text { RHS8 } 6181 \mathrm{~A} \mathrm{dE}^{*}=6.7 \quad 39.53 \\
\text { ISCC-NBS } 15 \text { MODERATE RED }\end{array}$ & $\begin{array}{l}\mathrm{MEN} \\
\mathbf{3 3 . 7 4}\end{array}$ & 10.26 & 35.27 & 16.9 \\
\hline
\end{tabular}

Fig. 3. Sample conversion of measured $\mathrm{Y}, \mathrm{x}, \mathrm{y}$ to CIELAB coordinates and a list of the closest RHS color chips. 
The translucence or opacity of a specimen bears on the choice of a backing or substrate. For opaque or nearly opaque specimens, the colorimeter measurements will be essentially the same regardless of whether the substrate is white, gray, or black. With translucent specimens, however, the choice of substrate will influence the color measurement. This influence can often be attenuated by using more than one thickness of the specimen over the substrate. For critical work, Hale recommends that the number of thicknesses be increased until further increase does not change the measured reflectance $(\mathrm{Y})$ by more than $2 \%$ of its previous value (W.N. Hale, personal communication).

For translucent specimens, a white tile (not the calibration plate!) should be used, even though some white paper gives excellent results. Paper or cloth substrates are not recommended, because these materials are often treated with optical "brighteners" that fluoresce under near ultraviolet radiation, a component of natural daylight and of the light source in many instruments (including the CR-300). Many of the "white" tiles sold by tile supply houses are noticeably off-white; some are yellowish, and some (which appear "whiter" than others) are bluish. One should obtain several different white tiles, measure their CIE coordinates, and select for use as substrates those with $\mathrm{x}$ and $\mathrm{y}$ values closest to the $\mathrm{x}$ and $\mathrm{y}$ coordinates of the white calibration plate supplied with the instrument.

Other considerations include the fact that the CR-300 integrates color over an area 8 $\mathrm{mm}$ in diameter; the eye, however, tends to identify lines or areas of different color present in the measurement field. An autumn leaf, e.g., may be mottled with translucent yellowish patches while the most prominent color is an opaque dark red; also, the veins may be a pale orange yellow. If areas are large enough, separate measurements may be made of the different colors. A similar problem arises in describing the color of certain azalea petals that seem to have a slight orange "haze" over the ground color. For a number of specimens I examined, this haze resulted from the presence in the petal epidermis of scattered cells with pigmentation differing from that in the bulk of the cells. In such circumstances, the integrated color measured by the instrument may still indicate the best color chip to use in a description, provided that distinctive characters are noted.

The size and shape of the surfaces for which color is to be evaluated may affect the choice of the instrument to be used. The 8-mmdiameter specimen aperture of the CR-300 colorimeter is suited to measure color on a wide range of plant materials. Large areas of color present no special problem with re- spect to the relation between area available for measurement and the accuracy of color determination. Measurements made with the CR-300 of specimens including bananas, apples, and a variety of leaves and petals yielded identification of the same RHS color chips as those selected by careful visual evaluation. Placing very small elements in a petri dish or jar lid to form an essentially uniform surface also yielded good results. In some cases (such as chrysanthemum or dahlia flowers, where the petals are smaller than the 8-mm-diameter aperture of the CR-300), several layers of the specimen material may be pressed lightly against the aperture of the instrument's light projection tube.

Substantial difficulties arise, however, in using an 8-mm specimen aperture for measuring objects similar in size and shape to Ilex, Nandina, and Pyracantha fruit. When several layers of these are placed in a shallow container, the surface presented to the instrument is very irregular. The surfaces in the top layer are domed and there are voids where the surfaces of adjacent fruits are not in contact. As a result of the square-law effect on the intensity of light reflected back to the instrument's plane of measurement, the increased scatter, and the absorption of light in the voids, the color chips selected based on colorimeter measurements will be darker and lower in chroma than those selected based on visual evaluation.

An additional problem occurs in associating the measurement of colors of very low chromaticity with the closest color chips. Such colors are usually "ish" whites, grays, or blacks, e.g., reddish gray, purplish black, or greenish white. These colors have very low $a^{*}$ and $b^{*}$ values, and hence are clustered around the origin (the intersection of the $\mathrm{a}^{*}$ and $b^{*}$ axes) of a CIELAB graph. When the computer program applies the color difference criterion, the chip closest to a reddish but nearly achromatic gray may be one on the other side of the origin - a greenish gray, e.g. The presence of such a crossover in hue can be readily detected by comparing the hue angle of the specimen color with the hue angle for each of the indicated chips. In some cases, simply using the "ish" modifier with white, gray, or black may be preferable to citing RHS color chips.

\section{Conclusions}

The method outlined and discussed in this article accomplishes two main objectives:

- Substituting instrumental measurement for visual color evaluation, thereby providing more accurate color notation and avoiding pitfalls of visual evaluation; and
- Linking the measurements to a widely used color chart appropriate for use in botany and horticulture.

The procedures described are applicable to a wide variety of specimens; exceptions include specimens very low in chromaticity and those of an inappropriate size and shape for an instrument's measuring aperture.

My interest in instrumental color evaluation for botanical and horticultural applications stems from personal experience with visual color evaluation and observing difficulties encountered by others. Reducing error attributable to human factors is desirable in identifying and recording color data, and instrumental measurement makes this possible. But few beyond specialists steeped in the practice of colorimetry receive a clear perception of color solely from the colorspace coordinates provided by the instrument. Hence, the added step of relating these coordinates to a color chart enables others to receive a direct visual impression of the specimen color, and is necessary for widespread application of instrumental color evaluation in botany and horticulture.

Readers interested in using the described method may contact me for further information on the color-chart measurements, formulas, and the APL functions used.

\section{Literature Cited}

American Society for Testing and Materials. 1991. D1729-89, Practice for visual evaluation of color differences of opaque materials. ASTM book of standards 14.02. Amer. Soc. Testing and Materials, Philadelphia.

Commission Internationale de l'Éclairage. 1978. Recommendations on uniform color spacescolor difference equations-psychometric color terms. Supplement 2, CIE Publ. 15 (E-1.3.1) 1971/ (TC-1.3), Bur. Centrale de la CIE, Paris.

Farnsworth, D. 1957. Manual: The FarnsworthMunsell 100-hue test for the examination of color discrimination (revised). Munsell Color, Baltimore.

Huse, R.D. and K.L. Kelly. 1984. A contribution toward standardization of color names in horticulture. Amer. Rhododendron Soc., Tigard, Ore. p. 7-15, 20-34. 39-41.

Judd, D.B. and G. Wyszecki. 1975. Color in business, science and industry. 3rd ed. Wiley, New York.

Kelly, K.L. and D.B. Judd. 1976. COLOR: Universal language and dictionary of color names. Natl. Bur. Standards Spec. Publ. 440. U.S. Govt. Printing Office, Washington, D.C.

Royal Horticultural Society. (1986?). Royal Horticultural Society colour chart. Royal Hort. Soc., London, and Flower Council of Holland, Leiden.

Tucker, A.O., M.J. Maciarello, and S.S. Tucker. 1991. A survey of color charts for biological descriptions. Taxon 40:201-214. 